Meeting report

\title{
13th Annual Congress of the European Society of Intensive Care Medicine, Rome, Italy, 1-4 October 2000 David Smith
}

\author{
Current science Ltd, London UK
}

Received: 12 October 2000

Accepted: 16 October 2000

Published: 24 October 2000
Crit Care 2000, 4:347-351

(c) Current Science Ltd (Print ISSN 1364-8535; Online ISSN 1466-609X)

\section{Introduction}

The theme of the congress was 'Time to audit and look ahead'. As with many of the major critical care meetings this year, the arrival of a new millennium was seen as a good opportunity to take stock of where the field of intensive care medicine stands, and also to assess where we are heading with our understanding and treatment of the critically ill.

\section{Genetic susceptibility to infection and sepsis}

It seems obvious that there must be a genetic component to the susceptibility of individuals to infection and also sepsis. The key question revolves around the relevance of any data indicating that there are indeed recognisable genetic polymorphisms that predispose individuals to either becoming infected, or having a disproportionate response to a bacterial insult.

Christian Brun-Buisson (Creteil, France) elegantly demonstrated that there are a number of clearly recognisable genetic polymorphisms associated with infection or sepsis. Work by Sorensen and co-workers [1] with a cohort of adoptees showed that there was a link between the death of the biological parents from infection and disease and their (environmentally dissociated) offspring. He also reported on work by Newport and co-workers [2] and Jouanguy and co-workers [3] showing that mutations in the interferon (IFN) $\gamma$ receptor 1 gene increased susceptibility to microbacterial infection. Similarly Yee and coworkers [4] showed that a polymorphism in the FcyRlla receptor could lead to an increased incidence of infection from encapsulated bacteria (the receptor is of key importance in the complement activation pathway). Additional evidence to support the case for the role of polymorphisms in infection and sepsis comes from work by Westendorp and co-workers [5] showing that polymorphisms in the plasminogen activator inhibitor (PAl-1) can be linked to outcome in patients.
Dr Brun-Bruisson contended that a serious search for, and study of, potential candidate polymorphisms could lead to novel treatments and possibly some prophylactic measures to minimise either susceptibility or the effects of infection.

Julian Bion (Birmingham, UK), whilst conceding immediately that genetic variability obviously has a role to play, posed the following questions: Is it important? Can it be measured? What interventions are available? The majority of patients presenting to the intensive care unit (ICU) with sepsis are, as a matter of course, well into the disease process. This challenges the relevance of susceptibility in the present day ICU, for if the knowledge of an individual's susceptibility is to be of any use, it is only relevant prior to admission to the ICU. Measurement of the effects of a polymorphism (particularly) in regard to a disease process like sepsis (a phenomenon driven by a multiple pathway) is very difficult indeed. Is the polymorphism exerting a direct effect on the disease process? Does it antagonise or complement another aspect of the disease process? Indeed, in polymorphisms occurring in a large proportion of the population [such as the angiotensin-converting enzyme (ACE) polymorphism, which may be associated with a variable outcome from myocardial infarction [6]], the question has to be asked: if it is so bad, why is it still found in such a high proportion of the population? The answer probably is that the negative effect of the gene under one set of circumstances is more than offset by the beneficial effect it exerts elsewhere. Another important point is that ICU practices have at least as much of an effect on outcome as any polymorphism.

The field of genetic testing is moving at a very fast pace however. It is now possible to place a set of genetic markers on a microchip and with the application of a blood or saliva sample, screen for thousands of genes simultaneously. In the not too distant future then, it may well be 
practical to have a quick and reliable test for any number of sepsis-related polymorphisms. A majority of the audience indicated that they would be quite happy to use such information. Whilst the desire to use every tool against sepsis is laudable, a moments thought is required. Dr Bion did touch on the ethical problems of using such information. How would you tell the patient what the genetic screen revealed? By definition, the data collected would have major implications for the children (planned or existing) of the patient. There are many more tricky ethical obstacles in the way of the use of such data. As the fields of genetics and molecular biology have shown, where gene data lead to probabilities and possibilities, the ethical minefield lies in wait.

\section{First presentation of the results of the international Phase III antithrombin III (ATIII) trial for severe sepsis, presented by Steven Opal (Baltimore, USA)}

Study objective

To see if replacement therapy with ATIII would achieve a significant increase in survival rate in patients with sepsis.

\section{Study design}

This was a randomised, double blind, multicentre trial. The expectation was that the placebo group would achieve a 28 day mortality rate of $45 \%$. The study was powered to detect a $15 \%$ reduction in 28 day mortality. A total of 2339 patients entered the trial. They were well matched for gender and other relevant characteristics and were randomised to the either the ATIII group (1157 patients) or the placebo group (1157 patients).

\section{Results}

Baseline measurements showed that the ATIII activity was $60 \%$ for both groups. After $24 \mathrm{~h}$, the placebo group still showed baseline ATIII activity, but in the ATIII group activity had risen to about $180 \%$.

At 28 days, mortality in the placebo group was $38.7 \%$ and in the ATIII group, 38.9\%. There were no differences between the two groups for new organ dysfunction or (ICU) survival. Subgroup analysis revealed no real differences for any of the analysed parameters but did indicate a treatment interaction with the use of heparin and ATIII in concert. Patients not receiving early treatment with heparin seemed to benefit slightly, with the trend becoming just statistically significant at 90 days.

Black patients seemed to suffer from ATIII treatment but further analysis indicated that this was probably a randomisation artifact since the black patients allocated to the ATIII group had higher simplified acute physiology (SAPS II) scores.

The Karnofsky scores (Table 1) for the two groups showed no differences at trial entry, or after 28 days. At
Table 1

\begin{tabular}{l} 
The Karnofsky score \\
\hline $\begin{array}{ll}100 \% & \text { Normal; no symptoms or signs of active disease } \\
90 \% & \begin{array}{l}\text { Able to carry on normal activity; minor signs or symptoms } \\
\text { of active disease }\end{array} \\
80 \% & \text { Normal activity with effort } \\
70 \% & \text { Unable to do active work; cares for self } \\
60 \% & \text { Requires occasional assistance } \\
50 \% & \quad \text { Requires considerable assistance and frequent medical } \\
& \quad \text { care } \\
40 \% & \text { Disabled; needs special care } \\
30 \% & \text { Hospitalized; death not imminent } \\
20 \% & \text { Hospitalized; critical condition } \\
10 \% & \text { Moribund } \\
0 \% & \text { Dead }\end{array}$ \\
\hline
\end{tabular}

56 and 90 days however, there was an indication of benefit from ATIII treatment for those patients who were alive and still in hospital for that length of time. There were no differences in the number of serious adverse events (multiple organ dysfunction, heart arrest, shock, etc).

One area in which differences were seen between the two groups was where major or minor bleeding occurred. In both cases the ATIII group suffered an increased number of incidences (statistically significant) and this was associated with a trend towards a worse outcome in cases of major bleeding. This was exacerbated further by heparin treatment.

\section{Conclusions}

There is no difference in mortality between the placebo and ATIII groups at 28,56 or 90 days. With the exception of the heparin results, subgroup analysis showed no differences.

When the data from the two groups were adjusted to reflect the SAPS II scores, there was a trend indicating that ATIII had some (not statistically significant) benefit on mortality.

\section{Eli Lilly Industrial symposia on 'The changing face of sepsis pathogenesis'}

Jean-Louis Vincent (Brussels, Belgium), Charles Esmon (Oklahoma City, USA) and Jean-Francois Dhainaut (Paris, France) highlighted the role, and the enormous treatment potential, of activated protein $C$ in sepsis. Research into treatments for sepsis has recently concentrated on three drugs: ATIII, tissue factor pathway inhibitor (TFPI) and recombinant human activated protein $\mathrm{C}$ (rhAPC). The results of the phase III trial with ATIII (above) indicate that 
this potential avenue of treatment is now no longer a viable one. The use of exogenous rhAPC to supplement the decreased levels of activated protein $C$ seen in patients with severe sepsis looks to have real potential. Initial work with animal models highlighted the possible use of rhAPC as a therapeutic agent. The Phase II trial results were good: trends towards improvements in systemic inflammatory response syndrome (SIRS)-, shock-, ventilator-, ICU and hospital-free days, as well as a drop in interleukin (IL)-6 levels (indicative of the anti-inflammatory properties of rhAPC) were seen. On the basis of these results, the phase III double blind, randomised, placebo controlled trial was started. The trial group were to be infused with $24 \mu \mathrm{g} / \mathrm{kg} / \mathrm{h}$ rhAPC over $96 \mathrm{~h}$. This was a multicentre trial conducted in $150 \mathrm{ICU}$ s on patients with severe sepsis. The primary end point was 28 day mortality with secondary end points being the assessment of the effect of rhAPC on organ dysfunction. The trial was stopped early when it became apparent that there was indeed a significant reduction in the 28 day mortality rate of patients treated with rhAPC. No actual data from the trial were presented as it still undergoing final analysis. There was however, this telling quote from Jean-Louis Vincent: 'The news is very very good'. This implies that there is a very significant reduction in mortality when patients with severe sepsis are given rhAPC. This is especially interesting since both ATIII and APC act in vivo to regulate the coagulation system. It would be interesting to know why the ATIII trial failed and the rhAPC trial looks to have been far more successful. The data from the rhAPC trial will be first presented at the 30th International Educational \& Scientific Symposium in San Francisco (10-14 February 2001) and then at the 21st International Symposium on Intensive Care and Emergency Medicine in Brussels (20-23 March 2001).

\section{Acute respiratory failure: where are we now?}

One of the major thematic sessions looked at the outcome of a number of randomised controlled trials (RCTs) in different aspect of acute respiratory failure (ARF). $\mathrm{Dr}$ Massimo Antonelli (Rome, Italy) began by assessing the evidence for the use of non-invasive ventilation (NIV) in patients with hypoxaemic respiratory failure. To date, some 48 studies have been conducted encompassing a total of 1343 patients. The results are encouraging: there appears to be a clear benefit with the use of NIV. The most recent of these trials has been reported on in Critical Care (Paper report: http://ccforum.com/paperview2_page.cfm? unique_id=5179). These RCTs are all limited by their small sample size and large scale trials are required before NIV can be recommended. Dr Antonelli announced his intention to start a large scale trial to investigate the use of NIV in patients with hypoxaemic ARF.

Peter Suter (Geneva, Switzerland), presented more sobering news on the results of trials investigating the effective- ness of pharmacological approaches to the treatment of ARF. His message was a simple one; nothing has been shown to be effective. Five anti-inflammatory compounds have been thoroughly investigated (procysteine, lysophylline, prostaglandin, ketoconazole and $\mathrm{N}$-acetylcysteine [Paper report: http://ccforum.com/paperview2_page.cfm? unique_id=1442 ]) and the results have been identical: no benefit. The use of inhaled nitric oxide, whilst improving gas exchange in $66 \%$ of patients, does not alter outcome in any significant way (Paper report: http://ccforum.com/ paperview2_page3.cfm?unique_id=2181). Similarly, surfactants also improve gas exchange, but again have no effect on outcome. There was some intriguing news to report in the use of sedation in ARF. Kress and coworkers demonstrated that they could wean patients more rapidly if they interrupted patient sedation on a daily basis [7] (Paper report: http://ccforum.com/paperview2_page. cfm?unique_id=5538). This would seem to indicate that aiming for the minimum necessary sedation, and coupling that with a daily assessment of the sedation requirement, is a worthwhile practice. There is the question of which sedative is best. A meta-analysis by Walder and coworkers (in press) indicates that propofol has a slight advantage over midazolam. Another possible treatment option may be late phase treatment with steroids (Paper report: http://ccforum.com/paperview2_page.cfm?unique_id=5578). Enrollment for the Late Steroid Rescue Study (LaSRS) is underway, with 75 out of the 200 patients required already into the study (data from ARDSnet http://www. ardsnet.org). Dr Suter indicated his belief that a lack of success with the anti-inflammatory compounds should not preclude further studies being undertaken. Perhaps altered dosing and delivery (during the phases of the disease) may yield results.

Luciano Gattinoni (Milan, Italy) presented data on the viability of proning as a treatment option. Whilst there was no difference in outcome at either 10 days or discharge from hospital, proning the patients did result in better oxygenation. Overall, proning is probably not justified as a treatment option, but it may be useful to 'buy time' in severe cases. Of course this may make no material difference, except to prolong the time to death.

One area where surfactants have had an effect is in treating respiratory distress syndrome (RDS) in premature infants. Thomas Wiswell (Philadelphia, USA) summarised the data on over $30 \mathrm{RCTs}$, the results showing that surfactant treatment decreases mortality as well as the severity of RDS. There is no effect on the incidence of chronic lung disease or neurological damage. There is currently a debate on whether prophylactic treatment or rescue therapy is better. Prophylactic treatment does give a better outcome in infants under 29 weeks, but then $40-60 \%$ of such infants do not need surfactant treatment. 


\section{Blood substitutes}

The panacea of a single universal blood substitute is probably an unattainable one. So research on blood substitutes is proceeding on a number of fronts with the aim of producing a number of products that are of value in specific situations.

Charles Wade (Sausalito, USA) presented data on the use of hypertonic saline dextran (HSD) in trauma patients as an initial fluid therapy. HSD consists of $7.5 \%$ $\mathrm{NaCl}$ in $6 \%$ Dextran 70. Initial trials with animal models gave good survival results but it must be noted that the trials were small and the population studied was heterogeneous. One important result is that HSD has good volume expansion characteristics: for every $1 \mathrm{ml}$ of HSD delivered, an expansion of about $1.3 \mathrm{ml}$ is achieved. This is true for both animal and human subjects. In human subjects, there is a trend for increased survival (not significant) at $24 \mathrm{~h}$, but more importantly, the survival to discharge increase is significant. Another important property is the ability of HSD to increase blood pressure (BP) over the first $30 \mathrm{~min}$ (this being the average transport time for a victim from the trauma scene to the ER). Dr Wade did speculate as to whether administration of a hypertonic solution would act to reduce the magnitude of the inflammatory response, thus accounting for the positive survival results, but noted that there was no direct evidence for this. Patients seem to be able to tolerate the $\mathrm{NaCl}$ loading that occurs upon administration of HSD. Another concern, that of the increase in BP breaking up any freshly formed blood clots particularly in head trauma patients, did not seem to be realised. HSD seems to be a good candidate for initial fluid therapy where there is a need to rapidly get volume into a patient to achieve some measure of stabilisation.

William Bickell (Tulsa, USA) elected to argue the case for the use of 'fresh full blood' and a more thoughtful approach to fluid resuscitation in patients with haemorrhagic shock. Drawing on data from the US army (dating back as far as the first world war) as well as his own work, he provided evidence that fresh whole blood gives the best clinical prognosis for recovery. As long as the $\mathrm{BP}$ is approximately $80 \mathrm{mmHg}$, the patient will be reasonably stable and delaying fluid resuscitation can increase survival rates. This was essentially a plea for some sense to be applied to the technology. Whilst the data were quite compelling, there is a problem with the supply of fresh (less than $72 \mathrm{~h}$ old) whole blood. Dr Bickell argued that if supply could meet demand in WWI then surely it should be possible in the 21 st century. However, it seems unsurprising that when there are very large numbers of people fighting each other in a small geographical area there is a ready supply of blood in large quantities.
There are two basic groups of oxygen substitutes; haemoglobin based molecules and perflourocarbons. Jean-Louis Vincent looked at haemoglobin based oxygen carriers. These may represent a useful tool in specific applications and may avoid a number of the known problems with the use of stored blood (viral infection, the age of the blood, etc). Modern haemoglobin solutions are polymers (haemoglobin cross-linked with another compound such as diaspirin). These avoid problems with renal toxicity and short persistence, and they also have right shifted oxygen dissociation curves. The haemoglobin can be either human (hard to obtain), bovine (very easy to obtain but with the potential for pathogenic contamination) or recombinant (very hard to manufacture). Oxygen substitutes also have a lower viscosity and a very small particle size (compared to a red blood cell), leading to better dissemination throughout the microvasculature. There are a number of potential problems to be overcome. Could the exposed haemoglobin be attacked by free radicals? Is the iron loading that accompanies transfusion with such blood substitutes a problem? Vasoconstriction is an issue, as is immunosuppression and platelet activation. Clinical trials with diaspirin cross-linked haemoglobin (DCLHb) have provided conflicting information, as Maurice Lamy (Liege, Belgium) explained. In one multicentre trial, patients who had undergone cardiac surgery received either packed RBCs or DCLHb. There was no difference in mortality, but an increased incidence of adverse events in the DCLHb group [8]. Sloan and coworkers conducted a trial on patients with severe haemorrhagic shock and noted a higher mortality rate in the patients administered DCLHb [9]. Whether this was due to the administration of DCLHb is not clear. There were baseline mortality rate differences between the two groups (the DCLHb group had a higher average Glasgow Coma Score) and there were more cardiac arrests in the DCLHb group. Like a number of trials, this was stopped early due to safety problems. One fact is apparent, the use of blood substitutes has enormous potential to bypass many problems associated with giving blood to critically ill patients. New products are being developed and a number of these are entering phase I and II trials. The possibility exists for there to be a number of products to be available 'off the shelf' to meet the specific requirements of the critically ill patient. Research into blood substitutes is heading in an exciting direction.

\section{Summary}

This is the 20th year of the European Congress. This year there was exceptional diversity and depth of both educational and 'hot-off-the-press' information for both scientists and clinicians. Nurses (often under-rated, but a vital part of the intensive care community) were also accommodated, with a special section of the congress dedicated to them. 
As we head off into the new century, all those who attended the conference have a good idea of what developments lie ahead in the field of intensive care medicine.

\section{References}

1. Sorensen TI, Nielsen GG, Andersen PK, Teasdale TW: Genetic and environmental influences on premature death in adult adoptees. N Engl J Med 1988, 318:727-732.

2. Newport MJ, Huxley CM, Huston S, Hawrylowicz CM, Oostra BA, Williamson R, Levin M: A mutation in the interferon-gamma-receptor gene and susceptibility to mycobacterial infection. $N$ Engl J Med 1996, 335:1941-1949.

3. Jouanguy E, Altare F, Lamhamedi S, Revy P, Emile JF, Newport M, Levin M, Blanche S, Seboun E, Fischer A, Casanova JL: Interferongamma-receptor deficiency in an infant with fatal bacille Calmette-Guerin infection. N Engl J Med 1996, 335:1956-1961.

4. Yee AM, Phan HM, Zuniga R, Salmon JE, Musher DM: Association between FcgammaRlla-R131 allotype and bacteremic pneumococcal pneumonia. Clin Infect Dis 2000, 30:25-28.

5. Westendorp RG, Hottenga JJ, Slagboom PE: Variation in plasminogen-activator-inhibitor-1 gene and risk of meningococcal septic shock. Lance, 1999, 354:561-563.

6. Keavney B, McKenzie C, Parish S, Palmer A, Clark S, Youngman L, Delepine M, Lathrop M, Peto R, Collins R: Large-scale test of hypothesised associations between the angiotensin-convertingenzyme insertion/deletion polymorphism and myocardial infarction in about $\mathbf{5 0 0 0}$ cases and $\mathbf{6 0 0 0}$ controls. International Studies of Infarct Survival (ISIS) Collaborators. Lancet 2000, 355:434-442.

7. Kress JP, Pohlman AS, O'Connor F, Hall JB: Daily interruption of sedative infusions in critically ill patients undergoing mechanical ventilation. N Engl J Med 2000, 342:1471-1477.

8. Lamy ML, Daily EK, Brichant JF, Larbuisson RP, Demeyere RH, Vandermeersch EA, Lehot JJ, Parsloe MR, Berridge JC, Sinclair CJ, Baron JF, Przybelski RJ: Randomized trial of diaspirin cross-linked hemoglobin solution as an alternative to blood transfusion after cardiac surgery. The DCLHb Cardiac Surgery Trial Collaborative Group. Anesthesiology 2000, 92:646-656.

9. Sloan EP, Koenigsberg M, Gens D, Cipolle M, Runge J, Mallory MN, Rodman G Jr: Diaspirin cross-linked hemoglobin (DCLHb) in the treatment of severe traumatic haemorrhagic shock: a randomized controlled efficacy trial. JAMA 1999, 282:1857-1864. 